DE

M E D I C I N A

T R O P I C A L

$\mathrm{DE}$

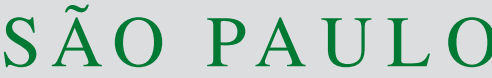

JOURNAL OF THE SÃO PAULO INSTITUTE OF TROPICAL MEDICINE

(1) Universidade Federal do Piauí, Centro de Ciências Agrárias, Programa de PósGraduação em Ciência Animal, Teresina, Piauí, Brazil

(2) Koninklijk Institut voor de Tropen, Biomedical Research, Amsterdam, Netherlands

(3) Universidade Estadual Paulista, Instituto de Biologia e Biomedicina, Departamento de Parasitologia, Botucatu, São Paulo, Brazil

(4) Universidade Federal do Piauí, Instituto de Doenças Tropicais Natan Portella, Laboratório de Leishmanioses, Teresina, Piauí, Brazil

Correspondence to: Ivete Lopes de Mendonça

Universidade Federal do Piauí,

Centro de Ciências Agrárias, Laboratório de Sanidade Animal, Campus da Socopo, CEP 64049-550, Teresina, PI, Brazil

E-mail: ivetemendonca@ig.com.br

Received: 27 September 2016

Accepted: 22 February 2017

\section{The performance of serological tests for Leishmania infantum infection screening in dogs depends on the prevalence of the disease}

Ivete Lopes de Mendonça', Joilson Ferreira Batista', Henk Schallig², Maria do Socorro Pires e Cruz ${ }^{1}$, Diego Peres Alonso ${ }^{3}$, Paulo Eduardo Martins Ribolla $^{3}$, Dorcas Lamounier Costa ${ }^{4}$, Carlos Henrique Nery Costa ${ }^{4}$

\section{ABSTRACT}

Dogs are considered the main reservoir of Leishmania infantum. This protozoan causes visceral leishmaniasis (VL), an uncontrolled urban zoonosis in Brazil. Serological tests and polymerase chain reaction (PCR) on peripheral blood were performed to identify infected dogs in scenarios of higher and lower prevalence of the disease (Teresina and Vitória). Onehundred infected and 57 non-infected animals from Teresina and 100 non-infected animals from Vitória were studied. Animal selection was not dependent on previous serology. The sensitivity (Teresina) and specificity (Teresina and Vitória) were as follows: indirect antibody fluorescence (IFAT) cut-off of 1:40 (IFAT 1:40): 96\%, 18\%, and 76\%; IFAT 1:80: 90\%, 33\%, and $93 \%$; direct agglutination test (DAT): $96 \%, 33 \%$, and $98 \%$; fast agglutination screening test (FAST): 93\%, 68\%, and 100\%; immunochromatographic assay with a recombinant rK39 antigen (rK39): 88\%, 74\%, and 98\%; enzyme linked immunosorbent assay (ELISA): 91\%, 79\%, and 98\%; rapid dual-path platform test (TR DPP ${ }^{\circledR}$ ): $98 \%, 60 \%$, and $98 \%$; and blood PCR: 29\%, 93\%, and 97\%, respectively. In the high transmission area, none of the tests adequately discriminated $L$. infantum-infected from non-infected dogs. However, in the high transmission city, the area under the receiver operating characteristic (ROC) curve of FAST, DAT, ICrK39, ELISA and TR DPP ${ }^{\circledR}$ was high

KEYWORDS: Visceral leishmaniasis. Leishmania infantum. Dogs. Diagnosis. Control.

\section{INTRODUCTION}

New World visceral leishmaniasis is caused by Leishmania (Leishmania) infantum (syn. L. (L.) chagasi) transmitted through the bite of infected female sand flies. Lutzomyia longipalpis, the main vector of the parasite in the Americas, is well adapted to urban and peri-urban environments ${ }^{1}$. Dogs may also get sick and are considered the main reservoir of the parasite and are responsible for disease maintenance, both in urban and peri-urban areas ${ }^{2}$. In Brazil, the disease became urban during the 1980s. Although the highest prevalence of human VL occurs in the Northeast region of the country; during the last 30 years, the disease has spread to new endemic areas in all regions of Brazil ${ }^{3}$.

The Brazilian VL surveillance and control program recommends periodic serological screening of all dogs, followed by the removal and sacrifice of those that are seropositive ${ }^{4}$. However, the accuracy on the identification of infected dogs remains controversial because they may not show clinical signs of the disease, which may delay early diagnosis ${ }^{5,6}$. Furthermore, community intervention was not 
significantly effective for the dog elimination strategy ${ }^{7}$. Recent systematic reviews stress that the effectiveness of such actions must be proven, in particular because several diagnostic assays fail to actually detect the infection ${ }^{8}$.

Several tests are used on the diagnosis of L. infantum infection in dogs. Although extensively evaluated with good results in the Old World and Brazil, for the serodiagnosis of $L$. infantum in dogs, direct agglutination test (DAT) and fast agglutination screening test (FAST) are not used in Brazil ${ }^{9-11}$. The Brazilian Ministry of Health distributes a rapid dual-path platform test (TR DPP ${ }^{\circledR}$ ) for screening, followed by enzyme linked immunosorbent assay (ELISA) for confirmation ${ }^{12}$. However, despite using three recombinant antigens (rK39, K26 and k9, fused together in a recombinant protein called $\mathrm{k} 28)^{13}$, TR $\mathrm{DPP}^{\circledR}$ sensitivity remains rather disappointing, particularly among sub-clinically infected animals ${ }^{14}$. By contrast, little is known about the performance of serological techniques in areas of distinct disease prevalence. Moreover, the specificity of both TR DPP ${ }^{\circledR}$ and ELISA can be low $^{15}$, thereby compromising the efficacy of these screening methods in Brazil. Additionally, several conventional serological tests are limited due to their cross reactivity with other parasitic diseases ${ }^{16}$. Therefore, more efficient tests must be identified and combined with others for the improved identification of naturally infected animals ${ }^{6}$. Then, more sensitive and specific tests may become new tools for the screening and confirmation of the disease, which could actually increase the effectiveness of this controversial VL control program.

Despite their lower sensitivity, laboratory methods considered gold standards for VL confirmation are parasitological approaches ${ }^{17}$. Detection of parasites in tissues, organs or cultures establishes the conclusive diagnosis of $L$. infantum infection in $\operatorname{dogs}^{12}$. However, in addition to the possibility of false-negative results due to the lack of sensitivity, these direct methods are difficult to perform and are invasive. Finally, concentration methods for direct examination, such as $\mathrm{QBC}^{\circledR}$, or faster parasitological exams, such as microculture, if automated, similar to bacterial culturing, may be useful in the near future ${ }^{18,19}$. Molecular methods are highly sensitive and specific, but have disadvantages of requiring more complex laboratory facilities, as well as more qualified technicians ${ }^{20}$.

To assess the diagnostic accuracy of different techniques to diagnose $L$. infantum infection in dogs, the present study evaluated the area under the curve (AUC), sensitivity, specificity and agreement of different serological tests used in routine laboratory settings and of an in-house polymerase chain reaction using peripheral blood (PCR blood). The study is unique since it does not use any prior serological screening for animal selection and it was performed in areas of higher and lower prevalence of $L$. infantum infection.

\section{MATERIALS AND METHODS}

\section{Study area}

The study was conducted in Teresina, Piaui State, Northeast Brazil, the city in which VL began its urbanization in the country over 30 years ago, as well as in Vitória, Espírito Santo State, Southeast coast, where VL had not been reported until the completion of this study; although recently, disease transmission has been identified in Vitória and the transmission of cutaneous leishmaniasis exists in its outskirts ${ }^{21,22}$. Teresina and Vitória are State capitals and have over 800,000 and 300,000 inhabitants, respectively. Three major epidemics of human visceral leishmaniasis have affected Teresina in the beginning of the 1980s, 1990s and 2000s.

\section{Animals}

The study included 257 domestic dogs of different breeds and ages, with and without compatible signs of canine visceral leishmaniasis (CVL). The number and types of signs varied largely, from localized to systemic, including pigmentation, ulcers, blepharitis, hairless areas, palpable lymph nodes, splenomegaly, paleness, wasting and bleeding. The animals were divided into three groups. The first group comprised 100 dogs with $(\mathrm{n}=89)$ and without $(\mathrm{n}=11)$ clinical signs of L. infantum infection, from Teresina, Veterinary Hospital of the Federal University of Piaui, donated by their owners for scientific study, all of which had Leishmania spp. amastigotes demonstrated in tissues. The second group consisted of 57 stray dogs with $(\mathrm{n}=10)$ and without $(\mathrm{n}=47)$ clinical signs of CVL, also from Teresina, in which Leishmania was not identified after extensive examination (see below). Finding such dogs was particularly troublesome due to the small number of dogs captured by public services at the time and also because parasites were found in many donated animals, leading to a less than expected sampling of non-infected animals in the endemic area. The third group comprised 100 stray dogs, with $(n=17)$ and without $(n=83)$ clinical signs suggestive of CVL, from Vitória, in which all parasitological examinations of bone marrow, lymph nodes, liver and spleen by culture method, as described below, were negative. The statistical power was over $88 \%$ for distinguishing proportions of $90 \%$ and $80 \%$ for a sample size comparing 100 with 100 dogs. When the sample size was adjusted to compare 100 with 57 dogs, the power was reduced to $86 \%$. The dogs from the two last groups were sacrificed to obtain livers and 
spleens for parasitological examination and identification of subclinical infection. These animals would be sacrificed by public services as part of the rabies control program.

\section{Clinical evaluation and sample collection}

After clinical evaluation by a veterinarian, $10 \mathrm{~mL}$ of blood were collected from the jugular vein for serology and $40 \mu \mathrm{L}$ of blood were collected from the tip of the ear on filter paper for DNA extraction (IsoCode ${ }^{\mathrm{TM}}$, Schleicher \& Schuell, Keene, NH). To obtain specimens for parasitological assessment, an aspiration biopsy from the bone marrow and popliteal lymph nodes and scrapings from intact or injured skin of the ears or nose were obtained. The samples were stained with Giemsa and studied using a $100 \mathrm{x}$ objective. After confirmation of Leishmania infection, the dogs were compassionately sacrificed, and aspiration biopsies of the liver and spleen were performed immediately. Sacrifice was performed by intravenous administration of ketamine hydrochloride $10 \%(15 \mathrm{mg} / \mathrm{kg})$ and acepromazine $0.2 \%$ $(0.5 \mathrm{mg} / \mathrm{kg})$. After sedation for approximately 15 minutes, $20 \mathrm{~mL}$ of $10 \%$ potassium chloride at $100 \mathrm{mg} / \mathrm{kg}$ were administered intravenously.

Bone marrow, popliteal lymph nodes, liver and spleen samples were inoculated in Novy-Macneal-Nicole (NNN) media enriched with insect Schneider's media, supplemented with $5 \%$ fetal bovine serum (inactivated at $56{ }^{\circ} \mathrm{C}$ for 30 minutes), $10 \mathrm{U} / \mathrm{mL}$ penicillin, and $10 \mathrm{mg} / \mathrm{mL}$ streptomycin. Cultures were incubated at $26^{\circ} \mathrm{C}$ in a BOD incubator. Every 5 days, cultures were examined using an optical microscope with a $40 \mathrm{x}$ objective to confirm the presence of Leishmania promastigotes, and this procedure was repeated until parasites were found (positive culture) or until day 30 of incubation, when, if no promastigotes were found, the cultures were considered negative.

\section{Indirect immunofluorescence reaction (IFAT)}

An indirect immunofluorescence kit for CVL (BioManguinhos, Rio de Janeiro, Brazil) was used. Serum samples were diluted from 1:40 to 1:640 in phosphate buffer saline (PBS) and tested. The cut-off points were 1:40 and 1:80 dilutions, which are the cut-off used in Brazil for the diagnosis of canine L. infantum infection and human diagnosis of visceral leishmaniasis.

\section{Enzyme-linked immunosorbent assay (ELISA)}

ELISA for canine VL (CVL) (Bio-Manguinhos, Rio de Janeiro, Brazil) was used. Serum samples were diluted 1:100, and tests followed the supplier's recommendations.

\section{Direct agglutination test (DAT)}

The protocol used for DAT (Royal Tropical Institute, Amsterdam, Netherlands) was described by Schallig et al. ${ }^{23}$. Sera were diluted from 1:50 to 1:51,200. After addition of samples, the plate was incubated in an orbital shaker at room temperature for 18 hours. The test was considered negative when compact blue dots formed on the bottom of the well, and the test was positive when there were large diffuse stains. The cut-off value was 1:400.

\section{Fast agglutination screening test (FAST)}

FAST (Royal Tropical Institute (Amsterdam, Netherlands) is a DAT variant and it is interpreted in the same way. The difference is the presence of a greater antigen concentration of $2 \times 10^{8}$ parasites $/ \mathrm{mL}$ and a single dilution (1:100), allowing a result in 4 hours $^{24}$.

\section{The rK39 immunochromatographic test}

The selected test was Kalazar Detect ${ }^{\mathrm{TM}}$ (InBios, Inc., Seattle, WA, USA), performed according to the manufacturer's instructions. This is a fast qualitative test characterized by a specifically adapted immunochromatographic assay for CVL diagnostic. It was conducted on paper strips and results were determined within 10 minutes.

\section{Dual-path platform fast test (TR DPP ${ }^{\circledR}$ )}

The selected test was a TR DPP ${ }^{\circledR}$ kit for CVL (Bio-Manguinhos, Rio de Janeiro, Brazil). It is also an immunochromatographic assay, but with three recombinant antigens (rK28). The tests were conducted using a serum sample following the manufacturer's protocol.

\section{Polymerase chain reaction (PCR)}

Filter papers with peripheral blood collected from the ears were placed in $1.5 \mathrm{~mL}$ Eppendorf tubes. Then, $500 \mu \mathrm{L}$ of ultra-pure water were added, stirred in a vortex and the tip of the Isocode ${ }^{\mathrm{TM}}$ was transferred to another sterile $0.5 \mathrm{~mL}$ microtube. Next, $100 \mu \mathrm{L}$ of ultra-pure water were added. The material was then heated in a hot water bath at $95^{\circ} \mathrm{C}$ for 30 minutes. At the end of the incubation, the sample was agitated in a vortex and the tip of the IsoCode ${ }^{\mathrm{TM}}$ was removed. The $100 \mu \mathrm{L}$ of eluate containing the sample DNA were stored at $-20{ }^{\circ} \mathrm{C}$ for further analysis. The method dismisses additional DNA extraction and it has been used for human L. infantum infection identification ${ }^{25}$. The NanoDrop ${ }^{\mathrm{TM}}$ apparatus 
(Thermo Scientific, Wilmington, USA) was used for DNA quantification.

The region between the $18 \mathrm{~S}$ and $5.8 \mathrm{~S}$ genes, known as ITS-1, from the rDNA was amplified using "LeF" (5' - TCCGCCCGAAAGTTCACCGA - 3') and "LeR" (5' - CCAAGTCATCCATCGCGACA - 3') primers. DNA amplification was performed in a final volume of $25 \mu \mathrm{L}$ containing $2.5 \mu \mathrm{L}$ of Taq polymerase $10 \mathrm{x}$ buffer $(160 \mathrm{mM}$ $\left(\mathrm{NH}_{4}\right)_{2} \mathrm{SO}_{4}, 670 \mathrm{mM}$ Tris-HCl pH 8.8 , and $0.1 \%$ Tween-20); $1.5 \mathrm{mM} \mathrm{MgCl} 2 ; 100 \mu \mathrm{M}$ of dATP, dCTP, dGTP and dTTP; $0.2 \mu \mathrm{M}$ of each primer; 0.5 units of Taq polymerase (Platinum $^{\mathrm{TM}}$ Taq DNA Polymerase, Invitrogen, Carlsbad, $\mathrm{CA}, \mathrm{EUA})$; and $5 \mu \mathrm{L}$ of DNA. The reactions were run in a Mastercycler Gradient ${ }^{\mathrm{TM}}$ (Eppendorf, Vienna, Austria) using the following program: initial denaturation of five minutes at $94{ }^{\circ} \mathrm{C}$, and 40 cycles of one minute at $94{ }^{\circ} \mathrm{C}$ for melting, 30 seconds for primer annealing, and 45 seconds at $72{ }^{\circ} \mathrm{C}$ for extension, and a final four minutes elongation at $72{ }^{\circ} \mathrm{C}$. Positive controls were DNA from cultured L. infantum from dog bone marrow. A $25 \mu \mathrm{L}$ mix containing all reagents, except DNA, was used as a negative control. DNA amplification was visualized by electrophoresis on $1 \%$ agarose gels stained with GeL Red ${ }^{\mathrm{TM}}$ (Biotium, Hayward, $\mathrm{CA})$, photographed under UV lights.

\section{Statistical analysis}

To estimate the sensitivity and specificity, the 95\% confidence interval for proportions (Cornfield), the kappa agreement index, and the ROC curves were calculated with Stata ${ }^{\circledR}$ software (College Station, TX, USA). Performance was evaluated by calculating the AUC, also with Stata ${ }^{\circledR}$. AUC is a plot of sensitivity versus false positive rate, which gives a precise estimation of the test performance. To estimate the post-test probability (the probability of infection after the test result), a Bayesian conditional probability model was used in a Microsoft ${ }^{\circledR}$ Excel spread sheet, Redmond, WA.

\section{RESULTS}

Table 1 shows the sensitivity, specificity and AUC for each diagnostic test. The sensitivity was high, except for blood PCR blood. The highest were: TR DPP ${ }^{\circledR}$ followed by IFAT 1:40 and DAT tests, and FAST. ELISA, IFAT 1:80 and rK39 presented intermediate sensitivity. Blood PCR detected less than $30 \%$ of the infected dogs.

The specificity was very different for the higher and lower transmission areas. In Teresina (high prevalence), the specificity values were very low for all tests, except for blood PCR. Specificity for ELISA and rK39 were modest and worse for FAST and TR DPP ${ }^{\circledR}$. The other tests were positive for most non-infected dogs. By contrast, in Vitória (lower prevalence), the specificity was excellent for FAST and DAT, rK39, ELISA and blood PCR. They were less relevant for IFAT 1:80 and modest for IFAT 1:40.

The test with the greatest AUC, in Teresina, although modest, was ELISA, followed by FAST, rK39 and TR DPP ${ }^{\circledR}$. The others presented disappointing results, with very little information for post-test probabilities. By contrast, the tests provided excellent information in Vitória. IFAT 1:40 and blood PCR provided less information.

Agreement among the tests, using separate specificities for the higher and lower transmission areas, was considerably greater in Vitória than in Teresina. According to a standard classification $^{26}$, in Teresina, none of the tests presented an excellent correlation, and the only reasonable to good agreements were between all pairs of tests for DAT, FAST, rK39, TR DPP $®$ and ELISA, and were poor for IFAT 1:40 and IFAT 1:80. Blood PCR presented poor agreement with all evaluated tests. However, in Vitória, agreement was excellent among all serological tests, except IFAT 1:40 (Table 2).

The presence of clinical signs had little impact on test performance and it was only associated with immunofluorescence assays. Among dogs with signs of disease, the sensitivity of IFAT 1:80 was higher (93\% versus $69 \%$ ), and in the lower transmission area, the specificity of IFAT 1:40 was significantly increased when there were signs of disease. The other tests were not changed by the presence of clinical presentation in any of the two cities (Table 3).

In the post-test probability simulation, in view of the pre-test probability (probability of infection before the test result, given by the prevalence or assessment on clinical and epidemiological grounds), the tests, when positive, were only relevant in Vitória. In Teresina, no test was sufficiently informative when positive, because they only slightly increased pre-test probabilities or prevalence. Additionally, in Teresina, for all tests, false-positive percentages were high, particularly when prevalence was below $20-40 \%$. In situations of high pre-test probability, tests contributed little to clinical diagnosis. Under these circumstances, IFAT 1:40 had the poorest performance, as measured by the AUC for serological tests (Figure 1A). However, when negative, IFAT 1:40 presented fewer false-negative dogs than the other tests (Figure 1B). Blood PCR also presented poor performance to exclude infections with a negative result.

In Vitória, FAST presented excellent results; however, with minimal pre-test or low prevalence probabilities (below 5\%), it increased post-test probabilities to over 90\%. A slightly worse performance was obtained for rK39, followed by ELISA, TR DPP ${ }^{\circledR}$ and DAT. IFAT 1:40 poorly 
Table 1 - Sensitivity, specificity and area under the indirect immunofluorescence reaction curve (IFAT) in the 1:40 and 1:80 dilutions, DAT and FAST direct agglutination tests, rK39 and TR DPP ${ }^{\circledR}$, ELISA and PCR of peripheral blood for the diagnosis of $L$. infantum infection in dogs in endemic and non-endemic areas

\begin{tabular}{|c|c|c|c|c|}
\hline Test & Place & $\begin{array}{l}\text { Sensitivity } \\
(95 \% \mathrm{Cl})^{*}\end{array}$ & $\begin{array}{l}\text { Specificity } \\
(95 \% \mathrm{Cl})\end{array}$ & $\begin{array}{l}\text { Area under the curve } \\
(95 \% \mathrm{Cl})\end{array}$ \\
\hline & Teresina $(\text { parasite }+)^{\star *}$ & $96(90-99)$ & & \\
\hline \multirow[t]{3}{*}{ IFAT 40} & Teresina (parasite -) & & $18(09-30)$ & $57(51-62)$ \\
\hline & Vitória & & $76(66-84)$ & $86(81-91)$ \\
\hline & Teresina (parasite + ) & $90(82-95)$ & & \\
\hline \multirow[t]{3}{*}{ IFAT 80} & Teresina (parasite -) & & $33(21-47)$ & $62(55-69)$ \\
\hline & Vitória & & $93(86-97)$ & $91(88-95)$ \\
\hline & Teresina (parasite + ) & $96(90-98)$ & & \\
\hline \multirow[t]{3}{*}{ DAT } & Teresina (parasite -) & & $33(21-47)$ & $65(58-71)$ \\
\hline & Vitória & & $98(93-99)$ & $97(95-99)$ \\
\hline & Teresina (parasite + ) & $93(86-97)$ & & \\
\hline \multirow[t]{3}{*}{ FAST } & Teresina (parasite -) & & $68(54-80)$ & $81(74-87)$ \\
\hline & Vitória & & $100(96-100)$ & $97(94-99)$ \\
\hline & Teresina (parasite + ) & $88(80-93)$ & & \\
\hline \multirow[t]{3}{*}{ rK39 } & Teresina (parasite -) & & $74(60-84)$ & $81(74-87)$ \\
\hline & Vitória & & $98(93-99)$ & $94(90-97)$ \\
\hline & Teresina (parasite + ) & $98(93-100)$ & & \\
\hline \multirow[t]{3}{*}{ TR DPP ${ }^{\circledR}$} & Teresina (parasite -) & & $60(46-72)$ & $79(72-85)$ \\
\hline & Vitória & & $98(93-100)$ & $98(96-100)$ \\
\hline & Teresina (parasite + ) & $91(84-96)$ & & \\
\hline \multirow[t]{3}{*}{ ELISA } & Teresina (parasite -) & & $79(66-89)$ & $84(79-91)$ \\
\hline & Vitória & & $98(93-100)$ & $94(91-98)$ \\
\hline & Teresina (parasite + ) & $29(21-40)$ & & \\
\hline \multirow[t]{2}{*}{ PCR blood } & Teresina (parasite -) & & $93(82-98)$ & $61(55-67)$ \\
\hline & Vitória & & $97(91-99)$ & $63(58-68)$ \\
\hline
\end{tabular}

* $95 \%$ confidence interval. ${ }^{* *}$ Parasitological exams.

Table 2 - Estimated concordance by the kappa index among diagnostic tests for L. infantum infection in endemic (Teresina, green) and non-endemic areas (Vitória, yellow)

\begin{tabular}{|c|c|c|c|c|c|c|c|c|}
\hline & IFAT 1:40 (\%) & FAT 1:80 (\%) & $\begin{array}{l}\text { DAT } \\
(\%)\end{array}$ & $\begin{array}{c}\text { FAST } \\
(\%)\end{array}$ & $\begin{array}{c}\text { rK39 } \\
(\%)\end{array}$ & TR DPP $^{\circledR}(\%)$ & ELISA (\%) & $\begin{array}{c}\text { PCR blood } \\
(\%)\end{array}$ \\
\hline IFAT 1:40 & & $\begin{array}{c}77 \\
(68-86)\end{array}$ & $\begin{array}{c}66 \\
(56-76)\end{array}$ & $\begin{array}{c}67 \\
(58-77)\end{array}$ & $\begin{array}{c}64 \\
(54-74)\end{array}$ & $\begin{array}{c}70 \\
(60-80)\end{array}$ & $\begin{array}{c}64 \\
(53-74)\end{array}$ & $\begin{array}{c}17 \\
(09-25)\end{array}$ \\
\hline IFAT 1:80 & $\begin{array}{c}60 \\
(43-78)\end{array}$ & & $\begin{array}{c}83 \\
(75-91)\end{array}$ & $\begin{array}{c}80 \\
(72-88)\end{array}$ & $\begin{array}{c}78 \\
(69-87)\end{array}$ & $\begin{array}{c}79 \\
(71-88)\end{array}$ & $\begin{array}{c}74 \\
(65-83)\end{array}$ & $\begin{array}{c}21 \\
(11-32)\end{array}$ \\
\hline DAT & $\begin{array}{c}24 \\
(03-45)\end{array}$ & $\begin{array}{c}36 \\
(17-56)\end{array}$ & & $\begin{array}{c}91 \\
(85-97)\end{array}$ & $\begin{array}{c}85 \\
(78-92)\end{array}$ & $\begin{array}{c}92 \\
(87-97)\end{array}$ & $\begin{array}{c}85 \\
(78-92)\end{array}$ & $\begin{array}{c}25 \\
(15-35)\end{array}$ \\
\hline FAST & $\begin{array}{c}27 \\
(12-42)\end{array}$ & $\begin{array}{c}33 \\
(17-49)\end{array}$ & $\begin{array}{c}48 \\
(33-63)\end{array}$ & & $\begin{array}{c}90 \\
(84-96)\end{array}$ & $\begin{array}{c}91 \\
(85-97)\end{array}$ & $\begin{array}{c}88 \\
(81-95)\end{array}$ & $\begin{array}{c}30 \\
(19-40)\end{array}$ \\
\hline rK39 & $\begin{array}{c}21 \\
(08-34)\end{array}$ & $\begin{array}{c}32 \\
(17-47)\end{array}$ & $\begin{array}{c}43 \\
(29-57)\end{array}$ & $\begin{array}{c}71 \\
(59-83)\end{array}$ & & $\begin{array}{c}87 \\
(80-94)\end{array}$ & $\begin{array}{c}88 \\
(81-95)\end{array}$ & $\begin{array}{c}28 \\
(17-39)\end{array}$ \\
\hline TR DPP ${ }^{\circledR}$ & $\begin{array}{c}22 \\
(05-39)\end{array}$ & $\begin{array}{c}32 \\
(15-50)\end{array}$ & $\begin{array}{c}40 \\
(23-58)\end{array}$ & $\begin{array}{c}51 \\
(36-66)\end{array}$ & $\begin{array}{c}54 \\
(40-68)\end{array}$ & & $\begin{array}{c}87 \\
(80-94)\end{array}$ & $\begin{array}{c}26 \\
(16-36)\end{array}$ \\
\hline ELISA & $\begin{array}{c}21 \\
(08-34)\end{array}$ & $\begin{array}{c}32 \\
(17-47)\end{array}$ & $\begin{array}{c}40 \\
(25-54)\end{array}$ & $\begin{array}{c}68 \\
(56-80)\end{array}$ & $\begin{array}{c}66 \\
(54-79)\end{array}$ & $\begin{array}{c}63 \\
(50-76)\end{array}$ & & $\begin{array}{c}28 \\
(17-38)\end{array}$ \\
\hline PCR blood & $\begin{array}{c}03 \\
(-04-07)\end{array}$ & $\begin{array}{c}-02 \\
(-09-05)\end{array}$ & $\begin{array}{c}05 \\
(-001-10)\end{array}$ & $\begin{array}{c}14 \\
(06-22)\end{array}$ & $\begin{array}{c}12 \\
(02-21)\end{array}$ & $\begin{array}{c}09 \\
(02-16)\end{array}$ & $\begin{array}{c}16 \\
(07-25)\end{array}$ & \\
\hline
\end{tabular}


Table 3 - Symptomatology association with the sensitivity, specificity and area under the curves of IFAT 1:40, IFAT 1:80, DAT, FAST, rK39, TR DPP ${ }^{\circledR}$, ELISA and PCR of peripheral blood for the diagnosis of canine L. infantum infection in endemic (Teresina) and non-endemic areas (Vitória)

\begin{tabular}{|c|c|c|c|c|c|c|}
\hline Test & $\begin{array}{l}\text { Presence of } \\
\text { symptoms }\end{array}$ & $\begin{array}{l}\text { Sensitivity } \\
(\text { IC 95\%) }\end{array}$ & $\begin{array}{c}\text { Specificity } \\
\text { (Teresina) } \\
\text { (IC 95\%) }\end{array}$ & $\begin{array}{l}\text { Area under the } \\
\text { curve (Teresina) } \\
\text { (IC 95\%) }\end{array}$ & $\begin{array}{l}\text { Specificity } \\
\text { (Vitória) } \\
\text { (IC 95\%) }\end{array}$ & $\begin{array}{l}\text { Area under the } \\
\text { curve (Vitória) } \\
\text { (IC 95\%) }\end{array}$ \\
\hline \multirow[t]{2}{*}{ IFAT 1:40 } & Asymptomatic & $85(55 ; 98)$ & $20(10 ; 33)$ & $52(41 ; 64)$ & $79(69 ; 87)^{\star}$ & $82(71 ; 93)$ \\
\hline & Symptomatic & $98(92 ; 100)$ & $00(00 ; 46)^{2}$ & $49(47 ; 50)$ & $44(14 ; 79)^{*}$ & $71(53 ; 88)$ \\
\hline \multirow[t]{2}{*}{ IFAT 1:80 } & Asymptomatic & $69(39 ; 91)^{*}$ & $35(22 ; 50)$ & $52(38 ; 67)$ & $95(88 ; 98)$ & $82(69 ; 95)$ \\
\hline & Symptomatic & $93(86 ; 97)^{\star}$ & $17(00 ; 64)$ & $55(38 ; 71)$ & $78(40 ; 97)$ & $85(71 ; 100)$ \\
\hline \multirow[t]{2}{*}{ DAT } & Asymptomatic & $92(64 ; 100)$ & $31(19 ; 46)$ & $62(52 ; 72)$ & $98(92 ; 100)$ & $95(87 ; 100)$ \\
\hline & Symptomatic & $97(90 ; 99)$ & $50(12 ; 88)$ & $73(51 ; 95)$ & $100(66 ; 100)^{2}$ & $98(96 ; 100)$ \\
\hline \multirow[t]{2}{*}{ FAST } & Asymptomatic & $85(55 ; 98)$ & $67(53 ; 79)$ & $76(64 ; 88)$ & $100(96 ; 100)^{2}$ & $92(82 ; 100)$ \\
\hline & Symptomatic & $94(87 ; 98)$ & $83(36 ; 100)$ & $89(72 ; 100)$ & $100(66 ; 100)^{2}$ & $97(95 ; 100)$ \\
\hline \multirow[t]{2}{*}{ rK39 } & Asymptomatic & $77(46 ; 95)$ & $71(56 ; 83)$ & $74(60 ; 87)$ & $99(94 ; 100)$ & $88(76 ; 100)$ \\
\hline & Symptomatic & $90(81 ; 95)$ & $100(54 ; 100)^{2}$ & $95(92 ; 98)$ & $100(66 ; 100)^{2}$ & $95(92 ; 98)$ \\
\hline \multirow[t]{2}{*}{ TR DPP ${ }^{\circledR}$} & Asymptomatic & $100(75 ; 100)$ & $59(44 ; 72)$ & $79(73 ; 86)$ & $99(94 ; 100)$ & $99(98 ; 100)$ \\
\hline & Symptomatic & $98(92 ; 100)$ & $67(22 ; 96)$ & $82(62 ; 100)$ & $89(52 ; 100)$ & $93(82 ; 100)$ \\
\hline \multirow[t]{2}{*}{ ELISA } & Asymptomatic & $100(75 ; 100)$ & $80(67 ; 90)$ & $90(85 ; 96)$ & $99(94 ; 100)$ & $99(98 ; 100)$ \\
\hline & Symptomatic & $90(81 ; 95)$ & $67(22 ; 96)$ & $78(57 ; 99)$ & $89(52 ; 100)$ & $89(78 ; 100)$ \\
\hline \multirow[t]{2}{*}{ PCR blood } & Asymptomatic & $46(19 ; 75)$ & $92(81 ; 98)$ & $69(55 ; 84)$ & $97(91 ; 99)$ & $71(57 ; 86)$ \\
\hline & Symptomatic & $26(18 ; 37)$ & $100(54 ; 100)^{2}$ & $63(59 ; 68)$ & $100(66 ; 100)^{2}$ & $63(59 ; 68)$ \\
\hline
\end{tabular}

(1) $95 \%$ confidence interval; (2) $97.5 \%$ one-sided confidence interval. * $p<0,05$

increased post-test probability, assigning to many healthy dogs a positive results (Figure 2A). In Vitória, all of the serological tests have also presented good performance for negative results, except for blood PCR, which was not useful when negative (Figure 2B).

\section{DISCUSSION}

This study showed that the level of $L$. infantum infection (or prevalence of transmission) in dogs affects the specificity of serological tests, excluding blood PCR. A critical characteristic was the selection of the study population, which used parasitological diagnosis instead of serological assays for screening, avoiding selection bias commonly seen in performance studies tests. This bias is due to the biological relationships of serological tests, which measure the amount of antibodies. In this way, the present findings are a true characteristic of serology for the diagnosis of L. infantum infection, because sensitivity estimates were not inflated by selection of animals that were previously seropositive and the specificities were not exaggerated by selection of animals known to be negative.

Despite the widespread belief that sensitivity and specificity are stable properties, this study shows that both, in particular specificity, are strongly influenced by infectious diseases prevalence. From 1995 to 2013, seroprevalence of $L$. infantum infection in dogs in Teresina shifted from $1.6 \%$ in 1996 to $41 \%$ in 2011, with an average prevalence of $9 \%$ per year. Introduced in 2006, the Brazilian strategy of measuring seroprevalences only in areas where human cases are registered certainly biased the prevalence estimations. In other endemic Brazilian cities, as well as in other countries, seroprevalences also varied widely, from $3 \%$ to $57 \%{ }^{27-30}$. Therefore, $L$. infantum infection estimated by seroprevalence among dogs is quite unstable in different locations, and over time in the same location.

TR DPP ${ }^{\circledR}$ presented the greatest sensitivity, although it was not significantly different from IFAT 1:40, DAT or FAST. With the lowest proportion of false-negatives, few infected dogs would remain in an area screened with TR DPP ${ }^{\circledR}$, confirming its choice as the standard screening test. In the city of Teresina, the most specific test was blood PCR, much more than the other tests, including ELISA, which is used as the confirmatory test in Brazil. However, ELISA had the best specificity among all of the serological tests in this high transmission scenario. IFAT 1:40, removed from the federal screening system since 2010, presented a very low specificity, indicating that most of the dogs that were eliminated during the 30 years of its use were actually uninfected animals. IFAT 1:80 and DAT also presented low specificity in Teresina. 


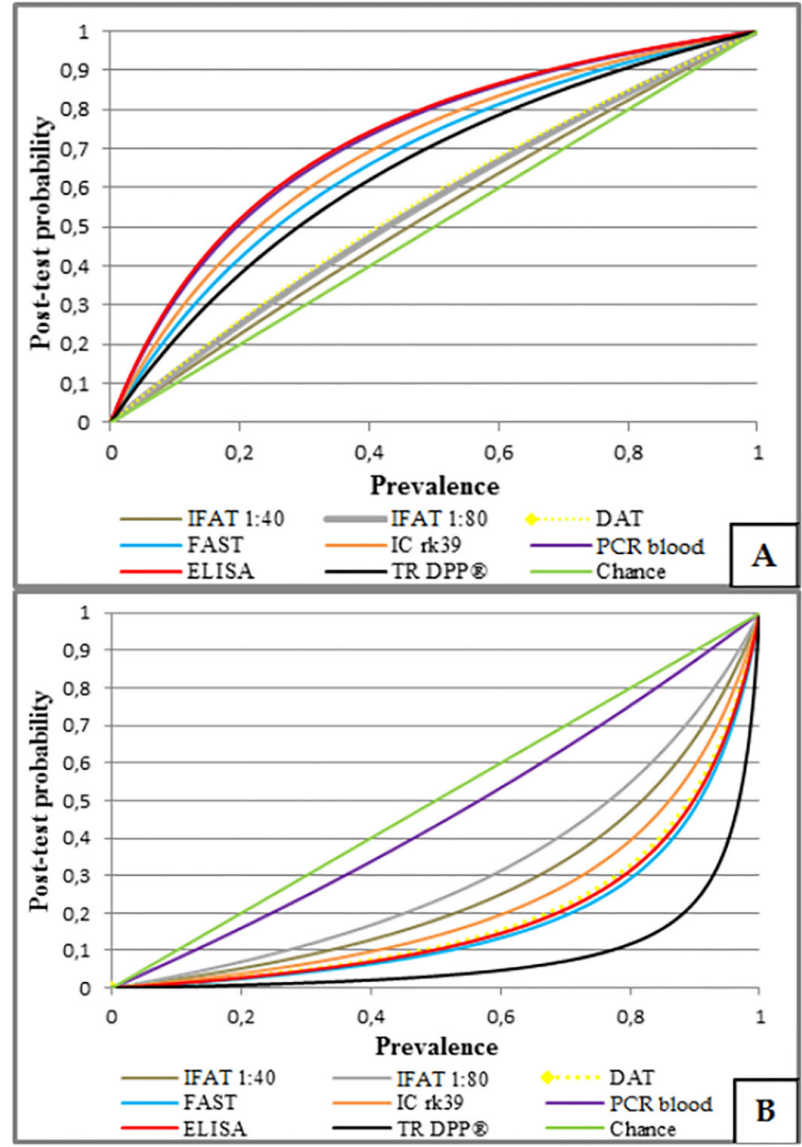

Figure 1 - Probability of having visceral leishmaniasis according to prevalence. Positive $(A)$ and negative results $(B)$ of the serological test, and PCR from peripheral blood from infected dogs from endemic regions and non-infected animals from endemic areas (Teresina). (Legenda) Brown: indirect immunofluorescence reaction titers $\geq 1: 40$; gray: indirect immunofluorescence titers $\geq 1: 80$; yellow: direct agglutination test (DAT); light blue: screening test for direct agglutination test (FAST); orange: immunochromatographic test with recombinant antigen (rK39); purple: polymerase chain reaction of -peripheral blood; red enzyme immunoassay (ELISA) black: fast test (TR $\left.\mathrm{DPP}^{\circledR}\right)$; and green: non-discrimination line

In Vitória, FAST was the most specific test, but it was not significantly different from DAT, TR DPP ${ }^{\circledR}$, ELISA or blood PCR. The higher specificity of blood PCR, together with its stability in Teresina and Vitória, suggests that if designed in an appropriate format for mass screening in poor resources regions, this would be a good candidate for $L$. infantum infection confirmation for dogs in the future.

None of the tests had a ROC that could be an excellent performance, in Teresina, according to an accepted classification ${ }^{31}$. ELISA had the greatest ROC curve, perhaps due to the balance between sensitivity and specificity, confirming the findings reported by Peixoto et al.$^{32}$. ELISA was followed by FAST and rK39. In contrast to Teresina, the tests performance in the lower transmission scenario was good, showing that the serological diagnosis of $L$. infantum

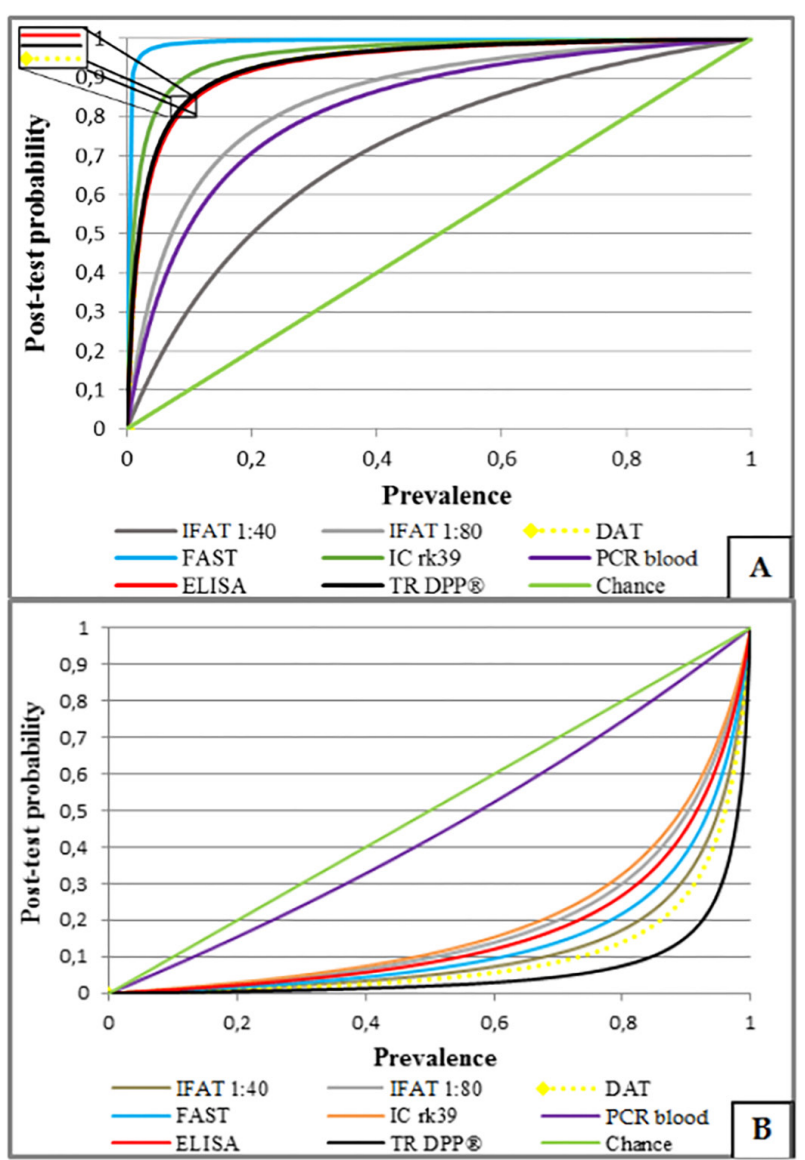

Figure 2 - Probability of having visceral leishmaniasis according to prevalence. Serological test positive results $(A)$ and negative results (B), and PCR from peripheral blood of infected dogs in an endemic region (Teresina) and non-infected animals from a non-endemic area (Vitória). (Legenda) Brown: indirect immunofluorescence reaction titers $\geq 1: 40$; gray: indirect immunofluorescence titers $\geq 1: 80$; yellow: direct agglutination test (DAT); light blue: screening test for direct agglutination test (FAST); orange: immunochromatographic test with recombinant antigen (rK39); purple: polymerase chain reaction of the peripheral blood; red enzyme immunoassay (ELISA) black: fast test (TR DPP ${ }^{\circledR}$ ); and green: non-discrimination line

infection in dogs in non-endemic areas is a good strategy. TR DPP ${ }^{\circledR}$ had the best discriminatory capacity, but all tests, except IFAT 1:40 and blood PCR were excellent. Nevertheless, with its high specificity, in Teresina and Vitória, the ability of blood PCR to identify $L$. infantum infection was weak in both scenarios, prohibiting its use as the sole screening test.

One of the most relevant results of this study is the mediocre performance of all serological tests in the high transmission setting of VL, whereas it was excellent in an area where the disease was not present or had low rates of prevalence. For serological tests, the most plausible explanation for the poor performance in the high transmission setting is that none of the tests could distinguish infection from immunity. In this manner, both 
ill and infective dogs have antibodies, as do dogs with subclinical infection before the illness presents itself and those that resolve the infection and remain immune ${ }^{33}$. It is not known which of these categories is the most common in endemic areas because the only study on the natural history of $L$. infantum infection was conducted with pups imported from non-endemic areas that, consequently, had no chance of having developed early natural immunity ${ }^{34}$. Therefore, this study shows that when the prevalence of disease increases, immune dogs generate false-positive results and decrease the serological specificity, and thus, the ROC curve area and likelihood ratio.

From the public health point of view, this study indicates greater caution when interpreting seroprevalences as the true prevalence. This is due to the variation of specificity according to prevalence ${ }^{35}$. Infection status estimates using non-serological tests through random surveys (instead of selective) may be the main instrument to correctly interpret serological results.

The use of confirmatory tests is the adopted strategy in Brazil to decrease the number of false positive culled dogs. However, the use of a second serological test as confirmatory in a system in which the screening test is also serological would not eliminate the false positive problem because both serological tests measure the same biological characteristic (antibodies) and are, therefore, strongly related, as this study shows. PCR improvement, kit development and standardization of molecular techniques for peripheral blood ${ }^{36}, \mathrm{skin}^{37}$, conjunctiva ${ }^{38}$, or all would ease this task. Similarly, the development of faster culture methods, such as microculture ${ }^{39}$ would also be very valuable. Furthermore, the weak association of illness and serology suggests that clinical signs may not be very helpful for predicting infection or infectiousness ${ }^{14,16}$.

Post-test probability exercise illustrates several epidemiological situations and may shed light on the best test to use. In the lower pre-test probability situation for screening dogs without clinical signs in endemic areas, the use of TR DPP ${ }^{\circledR}$ or FAST, followed by a molecular or parasitological test, may represent the best option due to the good specificity of PCR. An elevated pre-test probability in an endemic area represents a situation in which dogs have clinical evidence of disease, although this cannot add much information because the gain of post-test probability is small. However, a negative result substantially reduces the probability of infection. A lower pre-test probability occurs when testing animals with no or few signs of CVL in a nonendemic area. Under these circumstances, a positive result may confirm the diagnosis, but with the threat of $L$. infantum introduction in the area, a confirmatory diagnosis may be required. Finally, only a single positive test in a dog that is highly likely to have the disease in a non-endemic area is sufficient for establishing the final diagnosis, in the same way as a negative TR DPP ${ }^{\circledR}$ would exclude the diagnosis.

The most important study limitation is that the results cannot be directly applied to locations with unknown degrees of infection due to the instability of the serological performance. Another issue is the actual meaning of the dogs considered not to have $L$. infantum infection in an endemic area because they might have an actual but undetectable infection. Nonetheless, the specificity of blood PCR in the endemic area was high and statistically similar to that of the non-endemic area, suggesting that most of these animals were not infected and did not represent a transmission risk. Therefore, many seropositive dogs from endemic areas may be similar to those with other cryptic parasitic diseases, such as toxoplasmosis and erlichiosis. It is even possible that a portion of the population of seropositive dogs, identified in routine screening, represents a pool of resistant animals that increases herd immunity, in such a way that their removal could increase transmission ${ }^{40}$.

In conclusion, the specificity variation of serology according to prevalence requires random periodic surveys through non-serological tests to accurately measure the chance of infection of seropositive animals. It is indeed important to develop new mathematical models to obtain the true prevalence from seroprevalence. However, it is important to acknowledge that there has been considerable progress in the official strategy of using TR DPP ${ }^{\circledR}$ and ELISA in Brazil, compared to exclusive use of the ineffective IFAT $1: 40$. Although it is the most accurate of the tests, the use of serology as a confirmatory test for another serological test used for screening is controversial because it does not solve the false positive dilemma due to the high correlation between serological tests, such as for TR DPP ${ }^{\circledR}$ and ELISA. This challenge imposes the necessity of investing in research and technology in molecular or parasitic methods. Because of the lack of evidence that removing seroreactive dogs would decrease VL transmission, the poor performance of tests in Teresina stresses ${ }^{41}$ that Brazilian VL control program using seroreactive animal culling should be re-evaluated due to the weakness of the available technological tools.

\section{ACKNOWLEDGMENTS}

We are grateful to Teresina Zoonosis Management for the authorization for animal use in this study. We also thank Dr. Reinaldo Dietze, from the Department of Infectious Diseases of the Federal University of Espírito Santo, for his efforts to obtain dogs at the Zoonosis Control Center of Vitória. Finally, we are grateful to the excellent suggestions of Dr. Alexandre Reis and Dr. Guilherme Werneck. 


\section{ETHICAL STANDARDS}

The authors assert that all of the procedures contributing to this work comply with the ethical standards of the relevant national and institutional guides on the care and use of laboratory animals. The study was approved under the protocol $N^{\circ} 053 / 2008$ by the Ethical Committee on Animal Experimentation, of the Federal University of Piaui in August 15, 2008.

\section{CONFLICT OF INTERESTS}

Dr. Henk Schallig works at the Royal Tropical Institute that has developed DAT and FAST tests. There are no other conflicts of interest to be declared.

\section{REFERENCES}

1. Lainson R, Rangel EF. Lutzomyia longipalpis and the ecoepidemiology of American visceral leishmaniasis, with particular reference to Brazil: a review. Mem Inst Oswaldo Cruz. 2005;100:811-27.

2. Ready PD. Epidemiology of visceral leishmaniasis. Clin Epidemiol. 2014;6:147-54.

3. Harhay MO, Olliaro PL, Costa DL, Costa CH. Urban parasitology: visceral leishmaniasis in Brazil. Trends Parasitol. 2011;27:4039.

4. Brasil. Ministério da Saúde. Secretaria de Vigilância em Saúde. Departamento de Vigilância Epidemiológica. Manual de vigilância e controle da leishmaniose visceral. Brasília: Ministério da Saúde; 2004.

5. Grimaldi G Jr, Teva A, Santos CB, Ferreira AL, Falqueto A. The effect of removing potentially infectious dogs on the numbers of canine Leishmania infantum infections in an endemic area with high transmission rates. Am J Trop Med Hyg. 2012;86:966-71.

6. Lemos EM, Laurenti MD, Moreira MA, Reis AB, Giunchetti RC, Raychaudhuri S, et al. Canine visceral leishmaniasis: performance of a rapid diagnostic test (Kalazar Detect) in dogs with and without signs of the disease. Acta Trop. 2008;107:2057.

7. Werneck GL, Costa CH, de Carvalho FA, Pires e Cruz MS, Maguire JH, Castro MC. Effectiveness of insecticide spraying and culling of dogs on the incidence of Leishmania infantum infection in humans: a cluster randomized trial in Teresina, Brazil. PLoS Negl Trop Dis. 2014;8:e3172.

8. Romero GA, Boelaert M. Control of visceral leishmaniasis in Latin America: a systematic review. PLoS Negl Trop Dis. 2010;4:e584.

9. da Silva ES, van der Meide WF, Schoone GJ, Gontijo CM, Schallig HD, Brazil RP. Diagnosis of canine leishmaniasis in the endemic area of Belo Horizonte, Minas Gerais, Brazil by parasite, antibody and DNA detection assays. Vet Res Commun. 2006;30:637-43.

10. Schallig HD, da Silva ES, van der Meide WF, Schoone GJ, Gontijo CM. Didelphis marsupialis (common opossum): a potential reservoir host for zoonotic leishmaniasis in the metropolitan region of Belo Horizonte (Minas Gerais, Brazil). Vector Borne Zoonotic Dis. 2007;7:387-93.

11. Ferreira EC, de Lana M, Carneiro M, Reis AB, Paes DV, da Silva $\mathrm{ES}$, et al. Comparison of serological assays for the diagnosis of canine visceral leishmaniasis in animals presenting different clinical manifestations. Vet Parasitol. 2007;146:235-41.

12. Faria AR, Andrade HM. Diagnóstico da Leishmaniose Visceral Canina: grandes avanços tecnológicos e baixa aplicação prática. Rev Pan-Amaz Saude. 2012;3:47-57.

13. Pattabhi S, Whittle J, Mohamath R, El-Safi S, Moulton GG, Guderian JA, et al. Design, development and evaluation of rK28-based point-of-care tests for improving rapid diagnosis of visceral leishmaniasis. PLoS Negl Trop Dis. 2010;4:e822.

14. Grimaldi G Jr, Teva A, Ferreira AL, dos Santos CB, Pinto I, deAzevedo CT, et al. Evaluation of a novel chromatographic immunoassay based on Dual-Path Platform technology (DPP(R) CVL rapid test) for the serodiagnosis of canine visceral leishmaniasis. Trans R Soc Trop Med Hyg. 2012;106:54-9.

15. De Santis B, Santos EG, Souza CS, Chaves SA. Performance of DPPTM immunochromathographic rapid test (IRT) for canine visceral leishmaniasis: comparison with other serological methods in suspected dogs from Cuiabá, Mato Grosso State, Brazil. Braz J Vet Res Anim Sci. 2013;50:198-205.

16. Laurenti MD, de Santana Leandro MV Jr, Tomokane TY, De Lucca HR, Aschar M, Souza CS, et al. Comparative evaluation of the DPP $\left({ }^{\circledR}\right) \mathrm{CVL}$ rapid test for canine serodiagnosis in area of visceral leishmaniasis. Vet Parasitol. 2014;205:444-50.

17. Regina-Silva S, Fortes-Dias CL, Michalsky EM, França-Silva JC, Quaresma PF, da Rocha Lima AC, et al. Evaluation of parasitological examination, kDNA polymerase chain reaction and rK39-based immunochromatography for the diagnosis of visceral leishmaniasis in seropositive dogs from the screening-culling program in Brazil. Rev Soc Bras Med Trop. 2014;47:462-8.

18. Ates SC, Bagirova M, Allahverdiyev AM, Kocazeybek B, Kosan E. Utility of the microculture method for Leishmania detection in non-invasive samples obtained from a blood bank. Acta Trop. 2013;128:54-60.

19. Liarte DB, Mendonça IL, Luz FC, Abreu EA, Mello GW, Farias TJ, et al. QBC for the diagnosis of human and canine american visceral leishmaniasis: preliminary data. Rev Soc Bras Med Trop. 2001;34:577-81.

20. Solcà MS, Bastos LA, Guedes CE, Bordoni M, Borja LS, Larangeira DF, et al. Evaluating the accuracy of molecular 
diagnostic testing for canine visceral leishmaniasis using latent class analysis. PloS One. 2014;9:e103635.

21. Falqueto A, Sessa PA, Ferreira AL, Vieira VP, Santos CB, Varejão $\mathrm{JB}$, et al. Epidemiological and clinical features of Leishmania (Viannia) braziliensis American cutaneous and mucocutaneous leishmaniasis in the State of Espirito Santo, Brazil. Mem Inst Oswaldo Cruz. 2003;98:1003-10.

22. Tonini MA, Lemos EM, Reis AB, Vital WC, Dias ES, Dietze R. First description of autochthonous canine visceral leishmaniasis in the metropolitan region of Vitória, State of Espirito Santo, Brazil. Rev Soc Bras Med Trop. 2012;45:754-6.

23. Schallig HD, Canto-Cavalheiro M, da Silva ES. Evaluation of the direct agglutination test and the rK39 dipstick test for the sero-diagnosis of visceral leishmaniasis. Mem Inst Oswaldo Cruz. 2002;97:1015-8.

24. Schallig HD, Schoone GJ, Beijer EG, Kroon CC, Hommers M, Ozbel Y, et al. Development of a fast agglutination screening test (FAST) for the detection of anti-Leishmania antibodies in dogs. Vet Parasitol. 2002;109:1-8.

25. Costa CH, Stewart JM, Gomes RB, Garcez LM, Ramos PK, Bozza $\mathrm{M}$, et al. Asymptomatic human carriers of Leishmania chagasi. Am J Trop Med Hyg. 2002;66:334-7.

26. Rosner B. Fundamentals of biostatistics. $4^{\text {th }}$ ed. Belmont: Duxbury Press; 1995.

27. Silva MR, Marques MJ, Romanha AJ, Santa-Rosa IC, Carneiro $\mathrm{CM}$, Reis AB. Autochthonous canine visceral leishmaniasis in a non-endemic area: Bom Sucesso, Minas Gerais State, Brazil. Cad Saude Publica. 2008;24:281-6.

28. Falqueto A, Ferreira AL, dos Santos CB, Porrozzi R, da Costa MV, Teva A, et al. Cross-sectional and longitudinal epidemiologic surveys of human and canine Leishmania infantum visceral infections in an endemic rural area of southeast Brazil (Pancas, Espirito Santo). Am J Trop Med Hyg. 2009;80:559-65.

29. Franco AO, Davies CR, Mylne A, Dedet JP, Gállego M, Ballart $\mathrm{C}$, et al. Predicting the distribution of canine leishmaniasis in western Europe based on environmental variables. Parasitology. 2011;138:1878-91.

30. Schallig HD, Cardoso L, Semião-Santos SJ. Seroepidemiology of canine leishmaniosis in Évora (southern Portugal): 20-year trends. Parasit Vectors. 2013;6:100.

31. The area under a ROC curve. [cited 2015 Mar 01]. Available from: http://gim.unmc.edu/dxtests/roc3.htm.
32. Peixoto HM, de Oliveira MR, Romero GA. Serological diagnosis of canine visceral leishmaniasis in Brazil: systematic review and meta-analysis. Trop Med Int Health. 2015;20:334-52.

33. Lanotte G, Rioux JA, Perieres J, Vollhardt Y. Ecologie des leishmanioses dans le sud de la France. 10. Les formes évolutives de la leishmaniose viscérale canine. Elaboration d'une typologie bio-clinique à finalité épidémiologique. Ann Parasitol Hum Comp. 1979;54:277-95.

34. Courtenay O, Quinnell RJ, Garcez LM, Shaw JJ, Dye C. Infectiousness in a cohort of brazilian dogs: why culling fails to control visceral leishmaniasis in areas of high transmission. J Infect Dis. 2002;186:1314-20.

35. Gart JJ, Buck AA. Comparison of a screening test and a reference test in epidemiologic studies. II. A probabilistic model for the comparison of diagnostic tests. Am J Epidemiol. 1966;83:593602.

36. Coura-Vital W, Marques MJ, Veloso VM, Roatt BM, AguiarSoares RD, Reis LE, et al. Prevalence and factors associated with Leishmania infantum infection of dogs from an urban area of Brazil as identified by molecular methods. PLoS Negl Trop Dis. 2011;5:e1291.

37. Reis LE, Coura-Vital W, Roatt BM, Bouillet LE, Ker HG, Fortes de Brito RC, et al. Molecular diagnosis of canine visceral leishmaniasis: a comparative study of three methods using skin and spleen from dogs with natural Leishmania infantum infection. Vet Parasitol. 2013;197:498-503.

38. Geisweid K, Weber K, Sauter-Louis C, Hartmann K. Evaluation of a conjunctival swab polymerase chain reaction for the detection of Leishmania infantum in dogs in a non-endemic area. Vet J. 2013;198:187-92.

39. Allahverdiyev AM, Bagirova M, Cakir-Koc R, Elcicek S, Oztel ON, Canim-Ates S, et al. Utility of the microculture method in non-invasive samples obtained from an experimental murine model with asymptomatic leishmaniasis. Am J Trop Med Hyg. 2012;87:81-6.

40. Fox JP, Elveback L, Scott W, Gatewood L, Ackerman E. Herd immunity: basic concept and relevance to public health immunization practices. Am J Epidemiol. 1971;94:179-89.

41. Costa $\mathrm{CH}$. How effective is dog culling in controlling zoonotic visceral leishmaniasis? A critical evaluation of the science, politics and ethics behind this public health policy. Rev Soc Bras Med Trop. 2011;44:232-42. 